\title{
Cellulolytic potential of thermophilic species from four fungal orders
}

\author{
Peter Kamp Busk ${ }^{*}$ and Lene Lange
}

\begin{abstract}
Elucidation of fungal biomass degradation is important for understanding the turnover of biological materials in nature and has important implications for industrial biomass conversion. In recent years there has been an increasing interest in elucidating the biological role of thermophilic fungi and in characterization of their industrially useful enzymes. In the present study we investigated the cellulolytic potential of 16 thermophilic fungi from the three ascomycete orders Sordariales, Eurotiales and Onygenales and from the zygomycete order Mucorales thus covering all fungal orders that include thermophiles. Thermophilic fungi are the only described eukaryotes that can grow at temperatures above $45^{\circ} \mathrm{C}$. All 16 fungi were able to grow on crystalline cellulose but their secreted enzymes showed widely different cellulolytic activities, pH optima and thermostabilities. Interestingly, in contrast to previous reports, we found that some fungi such as Melanocarpus albomyces readily grew on crystalline cellulose and produced cellulases. These results indicate that there are large differences in the cellulolytic potential of different isolates of the same species. Furthermore, all the selected species were able to degrade cellulose but the differences in cellulolytic potential and thermostability of the secretome did not correlate to the taxonomic position. PCR amplification and sequencing of 22 cellulase genes from the fungi showed that the level of thermostability of the cellulose-degrading activity could not be inferred from the phylogenetic relationship of the cellulases.
\end{abstract}

Keywords: Thermophilic fungi; Endoglucanase; Cellobiohydrolase; Cellulolytic potential

\section{Introduction}

Fungi are important organisms for degradation of plant material in nature. They achieve this by means of secreted enzymes that are stable even under harsh environmental conditions. These same properties make the fungal enzymes suitable for industrial use. One example is fungal cellulases that are deployed in biorefineries for conversion of biomass to fermentable sugars and in the paper, textile and detergent industries (Karmakar and Ray 2011; Kuhad et al. 2011).

The cellulases are classified in the glycoside hydrolase (GH) families (www.cazy.org) (Henrissat and Davies 1997). Several different strategies involving many enzyme classes are used in natural degradation of recalcitrant biomass (Dashtban et al. 2009). However, industrial use of cellulases has mainly been focused on endo-1,4- $\beta$-Dglucanase and two types of cellobiohydrolases acting

\footnotetext{
*Correspondence: pkb@bio.aau.dk

Department of Biotechnology Chemistry and Environmental Engineering, Aalborg University, A.C. Meyers Vænge 15, 2450 Copenhagen, SV, Denmark
}

respectively from the reducing and from the non-reducing end of the polymer (Banerjee et al 2010). Additional industrially used cellulose-degrading enzymes are $\beta$ glucosidases, which degrade $\beta$-D-glucose oligomers to glucose and the GH61 proteins, which boost cellulose decomposition by oxidative degradation of the glucose polymer (Harris et al. 2010; Langston et al. 2011; Quinlan et al. 2011; Westereng et al. 2011).

Biomass decomposition by mesophilic fungi has been extensively studied (Dashtban et al. 2009). Whereas enzymes from mesophilic fungi are typically effective at $50^{\circ} \mathrm{C}$ several thermophilic fungi produce more thermostable enzymes that can be used at temperatures up to $70^{\circ} \mathrm{C}$ (Murray et al. 2004; Parry et al. 2002; Venturi et al. 2002; Voutilainen et al. 2008; Wojtczak et al. 1987). This high temperature stability is an important asset for industrial use. For example, it has been shown that a mixture of thermostable cellulases exhibits high lignocellulose degrading capacity with a temperature optimum of $65^{\circ} \mathrm{C}$ (Viikari et al. 2007). 
The known thermophilic fungi are either ascomycetes belonging to the orders Sordariales, Eurotiales, and Onygenales or zygomycetes of the order Mucorales (Berka et al. 2011; Morgenstern et al. 2012). These organisms are the only described eukaryotes that can grow at temperatures above $45^{\circ} \mathrm{C}$. In nature, thermophilic fungi are typically found in compost, wood chip piles, stored grains, animal dung and other environments that are self-heating due to degradation of plant materials (Johri et al. 1999). Although such material often contains high concentrations of cellulose some thermophilic fungi are poor cellulose-degraders and seem to utilize sugars released by cellulolytic species in the biotope (Maheshwari et al. 2000). Therefore, thermophilic fungi can differ greatly in their cellulolytic potential.

The thermophilic fungus Thermoascus aurantiacus of order Eurotiales has been studied intensively. It grows readily on cellulose (Romanelli et al. 1975) and produces thermostable cellulases and other enzymes (Gomes et al. 2000; Hong et al. 2003; Hong et al. 2007; Khandke et al. 1989; Parry et al. 2001; Parry et al. 2002). One of the interesting enzymes produced by $T$. aurantiacus is a copper-dependent monooxygenase of the GH61 family (Harris et al. 2010). Several GH61 proteins degrade cellulose by an oxidative mechanism thereby boosting the action of cellulases (Langston et al. 2011; Quinlan et al. 2011; Westereng et al. 2011). The GH61 from T. aurantiacus exhibits high activity in a boosting assay (Harris et al. 2010). The high cellulolytic potential of this fungus is underpinned by the report that extracellular enzymes from $T$. aurantiacus release the same amount of sugars from pretreated switchgrass as the commercial cellulase blend Cellic Ctec2 (Novozymes, Bagsvaerd, Denmark) at the same protein load (McClendon et al. 2012). In addition to the high activity, the T. aurantiacus enzymes have higher thermostability than Cellic Ctec2, which probably consists mostly of enzymes from mesophilic fungi although the precise composition has not been disclosed by the manufacturer.

Other thermophilic fungi that produce thermostable cellulases are Talaromyces emersonii (Murray et al. 2004; Voutilainen et al. 2010), Myceliophthora thermophila (Roy et al. 1990), Chaetomium thermophilum and Acremonium thermophilum (Voutilainen et al. 2008).

In the present study we investigated the cellulolytic potential of isolates of 16 thermophilic fungi. The fungi were selected from the three ascomycete orders Sordariales, Eurotiales and Onygenales and from zygomycete order Mucorales thus covering all orders which harbor thermophilic fungal species.

All 16 fungi were able to grow on crystalline cellulose but their extracellular enzymes showed widely different cellulolytic activities, $\mathrm{pH}$ optima and thermostabilities. Furthermore, we used PCR with degenerate primers to amplify and sequence gene fragments of 22 new cellulases from these fungi. The phylogenetic relationship of the enzymes showed a better correlation to the fungal order than to the thermostability of the fungal cellulosedegrading activity.

\section{Materials and methods}

\section{Fungi and growth conditions}

Fungi were purchased from Centraalbureau voor Schimmelcultures, Utrecht, The Netherlands (Table 1). Unless otherwise indicated, growth experiments on different carbon sources were done essentially as described (Herr 1979). Briefly, the fungi were grown on minimal medium with $1 \%$ glucose for 3 days. Next, $500 \mu$ lof this culture was transferred to $5 \mathrm{ml}$ of basal medium supplemented with the indicated carbon source with or without $0.5 \%$ yeast extract. The cultures were incubated with shaking (250 $\mathrm{rpm}$ ) for the time indicated. The growth temperature was $45^{\circ} \mathrm{C}$ except for $T$. emersonii and Scytalidium thermophilum that were incubated at $37^{\circ} \mathrm{C}$.

For DNA purification the fungi were grown on $6 \%$ wheat bran (Finax, Esbjerg, Denmark), $1.5 \%$ agar (SigmaAldrich, Cambridge, UK) plates at the recommended temperature.

\section{Endoglucanase assay}

Endoglucanase activity was measured with Azo-CM-Cellulose (cat. S-ACMC, Megazyme, Bray, Ireland) as substrate in an assay modified from the manufacturer's protocol. A culture broth sample of $20 \mu \mathrm{l}$ was mixed with $20 \mu \mathrm{l}$ of $2 \%$ Azo-CM-Cellulose in $2 \times$ McIlvaine Buffer (McIlvaine 1921) at the desired $\mathrm{pH}$. The culture broth sample was incubated at the indicated time and temperature before mixing with $100 \mu \mathrm{l}$ of precipitant (300 mM Na acetate, 18 $\mathrm{mM} \mathrm{Zn}$ acetate, $76 \% \mathrm{EtOH}$ ( $\mathrm{pH} 5)$ ). The stopped reactions were centrifuged $16,000 \mathrm{~g}$ for 1 minute and $100 \mu \mathrm{l}$ of the supernatant was dried down at $80^{\circ} \mathrm{C}$ and resuspended in $5 \mu \mathrm{l}$ of water. Finally, the absorption at $600 \mathrm{~nm}$ was measured and enzyme activity was calculated as described (Megazyme, Bray, Ireland).

\section{Filter paper assay}

Degradation of filter paper was measured by first cutting a $5 \times 5 \mathrm{~mm}$ piece of filter paper \#1 (Whatman, Kent, UK) with a pair of sharp scissors whereafter it was submerged in $80 \mu \mathrm{l}$ of 1.25x McIlvaine Buffer (Mcllvaine 1921) at the desired $\mathrm{pH}$. Next, $20 \mu \mathrm{l}$ of sample was added and the assay was incubated at the indicated time and temperature. The filter paper was removed and $0.3 \mu \mathrm{l}$ of Novozym 188 (Novozymes, Bagsvaerd, Denmark) was added and the sample incubated for 30 minutes at $50^{\circ} \mathrm{C}$ to convert any cellobiose to glucose. The reactions were centrifuged $16,000 \mathrm{~g}$ for 1 minute and the supernatant was dried down at $80^{\circ} \mathrm{C}$ and resuspended in $5 \mu \mathrm{l}$ of water. Finally, the 
Table 1 List of fungi and growth on cellulose

\begin{tabular}{|c|c|c|c|c|c|}
\hline Order & Name & CBS no. $^{a}$ & Isolated from & $\begin{array}{l}\text { Growth } \\
\text { on Avicel }\end{array}$ & $\begin{array}{l}\text { Abbreviation } \\
\text { used in figs. }\end{array}$ \\
\hline Sordariales & Chaetomium senegalense & 728.84 & Plant remains & Poor & Chsene \\
\hline Sordariales & Chaetomium thermophilum & 180.67 & Typha, incubated strawand leaf mold & Yes & Chther \\
\hline Sordariales & Corynascus thermophilus & 406.69 & Mushroom compost & Yes & Cother \\
\hline Sordariales & Melanocarpus albomyces & 638.94 & Chicken nest straw & Yes & Malbo \\
\hline Sordariales & Remersonia thermophila & 540.69 & Mushroom compost During peak heating & Yes & Rether \\
\hline Sordariales & Scytalidium indonesiacum & 259.81 & Soil & Yes & Sindo \\
\hline Sordariales & Scytalidium thermophilum & 620.91 & Saw dust\&wood chips In pighouse bedding & Yes & Sther \\
\hline Onygenales & Malbranchea cinnamomea & 115.68 & Oryza sativa (Gramineae) seeds & Yes & Mcinn \\
\hline Eurotiales & Talaromyces byssochlamydoides & 151.75 & Desert soil & Poor & Tbyss \\
\hline Eurotiales & Talaromyces emersonii & 393.64 & Compost & Yes & Temer \\
\hline Eurotiales & Talaromyces leycettanus & 398.68 & Coal spoil tip soil & $+Y E^{C}$ & Tleyc \\
\hline Eurotiales & Talaromyces thermophilus & 236.58 & Decaying Parthenium argentatum & Yes & Tther \\
\hline Eurotiales & Thermoascus aurantiacus & 891.70 & Wood & $+Y E^{c}$ & Taura \\
\hline Eurotiales & Thermomyces lanuginosus & 632.91 & Rotting guayule shrub & Yes & Tlanu \\
\hline Mucorales & Rhizomucor miehei & 182.67 & Retting Parthenium argentatum & Yes & Rmie \\
\hline Mucorales & Thermomucor indicae-seudaticae & 104.75 & Municipal compost & Yes & Tindi \\
\hline
\end{tabular}

${ }^{\mathrm{a} S}$ Strain registration number at Centraalbureau voor Schimmelcultures.

${ }^{\mathrm{b}} \mathrm{Good}$ growth on avicel with $0.5 \%$ yeast extract.

'Only growth on avicel with $0.5 \%$ yeast extract.

glucose content of the sample was measured with the D-Glucose HK Assay Kit (Megazyme, Bray, Ireland).

\section{DNA purification}

Fungal mycelium was scraped of the top of a wheat bran agar plate, frozen in $\mathrm{N}_{2}(\mathrm{l})$ and ground with a mortar and pestle. DNA was extracted from the homogenized mycelium with the Fungal DNA Mini Kit (Omega Bio-Tek, Norcross, GA, USA) according to the manufacturer's instructions.

\section{RNA purification}

Fungal mycelium was collected by filtration of liquid cultures through Miracloth (Calbiochem, San Diego, CA, USA) and RNA was purified with a Total RNA kit (A\&A Biotechnology, Gdynia, Poland) or with Tri Reagent (Sigma-Aldrich, St. Louis, MO, USA).

\section{Design of degenerated primers}

For each of the glycoside hydrolase families 6 (GH6), 7 (GH7) and 45 (GH45) the most conserved hexapeptides were found in thermophilic and thermotolerant fungal enzymes available in GenBank. These hexapeptides were reverse translated according to the genetic code. Positions containing any nucleotide (A, C, G or T) were substituted with inosine (Table 2). Degenerate nucleotides at the 3' end of the primers were removed from the sequence of the primers. Reverse primers were designed to be complementary to the DNA sequence encoding the hexapeptide.
Table 2 Sequence of conserved peptides and PCR primers

\begin{tabular}{lll}
\hline Target & Peptide & Primer sequence $^{\text {a }}$ \\
\hline GH6 & LPDRDC & CAGGTCCTICCIGAYMGIGAYTG \\
GH6 & GWLGWP & CAGGTCGGITGGCTIGGITGGC \\
GH6 & GLATNV & CAGGTCGGICTIGCIACIAAYGT \\
GH6 & PAPEAG & CAGGTCCIGCYTCIGGIGCIGG \\
GH6 & WFQAYF & CAGGTCAARTAIGCYTGRAACCA \\
GH6 & WVKPGG & CTGGACCCICCIGGYTTIACCCA \\
GH6 & GLATNV & CAGGTCGGICTIGCIACIAAYGT \\
GH6 & WYDLP & CTGGACGTIGTITAYGAYCTICC \\
GH7 & DANWRW & CTGGACGAYGCIAAYTGGMGITGG \\
GH7 & EFTFDVD & CTGGACGARTTYACITTYGAYGTIGA \\
GH7 & GTGYCD & CTGGACGGIACIGGITAYTGYGA \\
GH7 & EMDIWEA & CTGGACGCYTCCCADATRTCCATYTC \\
GH7 & DGCDFN & CTGGACTTRAARTCRCAICCRTC \\
GH7 & WTQF & CTGGACAAYTGIGTIACIAC \\
GH45 & YWDCCK & CAGGTCTAYTGGGAYTGYTGYAA \\
GH45 & PGGGVG & CAGGTCCCIACICCICCICCIGG \\
GH45 & WR(F/Y)(D/N)WF & CAGGTCAACCARTTRTAICKCCA \\
GH45 & WCCACY & CTGGACTARCAIGCRCARCACCA \\
GH45 & WCCACY & CTGGACTGGTGYTGYGCITGYTA \\
GH45 & WDCCKP & CTGGACTGGGAYTGYTGYAARCC \\
\hline
\end{tabular}

${ }^{\mathrm{a}}=$ Inosine, $\mathrm{Y}=\mathrm{C}$ and $\mathrm{T}, \mathrm{K}=\mathrm{G}$ and $\mathrm{T}, \mathrm{M}=\mathrm{A}$ and $\mathrm{C}, \mathrm{R}=\mathrm{A}$ and $\mathrm{G}$. 
A tail of six bases (CTGGAC) was added to the $5^{\prime}$ end of all primer sequences as this improves the performance of short primers (Andersen et al. 2000; Balcells et al. 2011; Chen et al. 2005).

The primers were synthesized and HPLC-purified by Sigma-Aldrich (Cambridge, UK).

\section{PCR with degenerated primers}

A mix of 100 ng total fungal DNA in 1x Run PCR buffer, $2 \mathrm{mM}$ each dATP, dCTP, dGTP and dTTP, $400 \mathrm{nM}$ forward primer; $400 \mathrm{nM}$ reverse primer; $1 \mathrm{U}$ RUN DNA polymerase (A\&A Biotechnology, Gdynia, Poland) in a total volume of $20 \mu \mathrm{l}$ was used for PCR on an MyCycler (Bio-Rad, Hercules, CA, USA) with the following thermal profile:

Initial denaturation $95^{\circ} \mathrm{C}, 5$ minutes.

30-40 cycles of $95^{\circ} \mathrm{C}, 20$ seconds; annealing temperature, 30 seconds; $72^{\circ} \mathrm{C}, 60$ seconds and a final extension at $72^{\circ} \mathrm{C}$ 5 minutes.

The number of cycles and the annealing temperature was optimized for each primer set (Table 2).

PCR products were analyzed by agarose gel electrophoresis and selected DNA were cut out and purified with the Qiaquick kit (Qiagen, Hilden, Germany).

One $\mu$ l of the purified PCR product was reamplified in a $50 \mu \mathrm{l}$ reaction under the same conditions as the original PCR except that only 15 to 20 cycles of PCR were performed.

\section{RT-PCR and RACE}

FirstChoice ${ }^{\curvearrowleft}$ RLM-RACE Kit (Invitrogen, Grand Island, NY, USA) was used for cDNA synthesis and RACE according to the manufacturer's protocol.

For RT-PCR $1 \mu$ of the RACE cDNA reaction was used for PCR in a final volume of $20 \mu$ containing $1 x$ Run PCR buffer, $2 \mathrm{mM}$ each dATP, dCTP, dGTP and dTTP, $500 \mathrm{nM}$ forward primer; $500 \mathrm{nM}$ reverse primer; $1 \mathrm{U}$ RUN DNA polymerase (A\&A Biotechnology, Gdynia, Poland) on an MyCycler (Bio-Rad, Hercules, CA, USA) with the following thermal profile:

Initial denaturation $95^{\circ} \mathrm{C}, 5$ minutes.

30 cycles of $95^{\circ} \mathrm{C}, 30$ seconds; $60^{\circ} \mathrm{C}, 30$ seconds; $72^{\circ} \mathrm{C}$, 60 seconds and a final extension at $72^{\circ} \mathrm{C} 5$ minutes.

PCR products were analyzed by agarose gel electrophoresis.

\section{Sequencing and analysis}

PCR products were cycle sequenced by Eurofins-MWG (Ebersberg, Germany) or StarSEQ (Mainz, Germany) with one of the degenerated primers used for PCR.

The resulting sequences were translated to amino acid sequence and used for BLAST search (Altschul et al. 1997) against the non-redundant protein sequence database at NCBI and inspected for conserved domains
(Marchler-Bauer et al. 2011) in the CDD database at NCBI.

Sequence alignment was made with ClustalW (Larkin et al. 2007) and adjusted manually. Phylogenetic trees were made with MUSCLE, PhyML and TreeDyn at Phylogeny.fr (Dereeper et al. 2008).

\section{Statistical analysis}

P-values were calculated by two-sided Student's T-test or by analysis of variance tests (ANOVA) unless indicated otherwise.

\section{Nucleotide sequence accession numbers}

The DNA sequences of the product of PCR amplification have been deposited in the European Nucleotide Archive databases [EMBL:HG313865, HG313866, HG313868, HG313869, HG313871 - HG313874, HG313876 HG313881 and HG313883 - HG313889].

\section{Results}

To characterize and compare the cellulolytic potential of thermophilic fungi we chose one isolate of each of 16 (according to the provider) non-pathogenic, non-toxinproducing thermophilic fungi.

A medium with microcrystalline cellulose as the only carbon source was inoculated with each of the 16 fungal strains to test their ability to grow on cellulose. All of the fungi could grow on the microcrystalline cellulose. However, Talaromyces leycettanus and T. aurantiacus needed a supplement of $0.5 \%$ yeast extract for growth (Table 1). Also Chaetomium senegalense and Talaromyces byssochlamydoides grew better when the cellulose minimal medium was supplemented with yeast extract.

To assess the cellulolytic potential of the fungi when grown on microcrystalline cellulose samples of culture medium were removed at various times and assayed for endoglucanase activity. All of the fungi produced measurable levels of endoglucanase activity except $S$. thermophilum, T. byssochlamydoides and Talaromyces thermophilus where no endoglucanase activity was detectable in the medium (Figure 1) although these fungi grew well on cellulose (Table 1).

Of the 13 fungi where endoglucanase activity was detected the activity measured in the medium from $T$. leycettanus was more than five times higher than from $M$. albomyces $(P<0.001$, Student's T-test), which had the second highest endoglucanase activity of the fungi used in the present study (Figure 1).

The $\mathrm{pH}$ optimum of the endoglucanase activity of each fungus was determined by performing the assay at different $\mathrm{pH}$ values (Figure 2). Most of the fungal endoglucanases had optimal activity at $\mathrm{pH} 4-6$ but the highest activity of the endoglucanase from Thermomucor indicae-seudaticae was measured at $\mathrm{pH} 8$. 


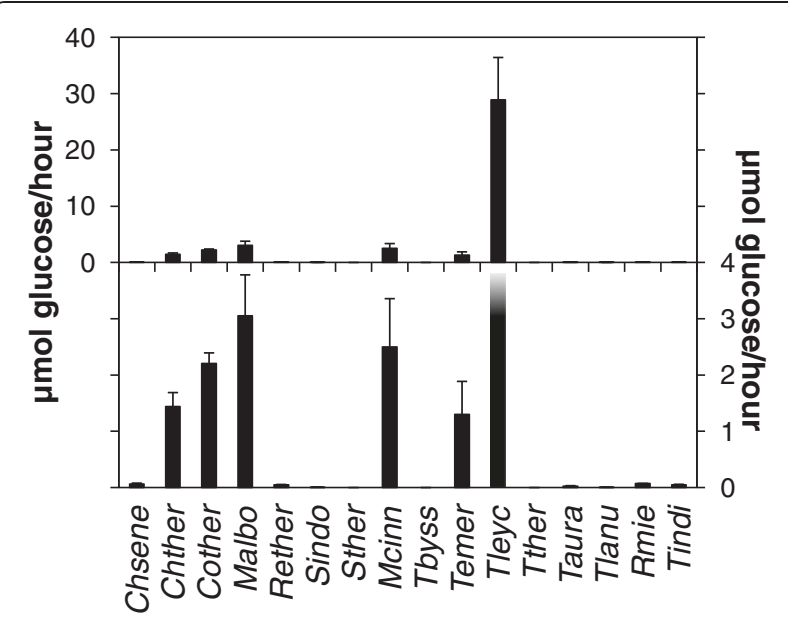

Figure 1 Secreted endoglucanase activity from 16 thermophilic fungi grown on microcrystalline cellulose. Endoglucanase activity of secreted fungal enzymes was measured as described in "Methods". The left y-axis indicates the scale for the upper panel including endoglucanase activities from all the fungi and the right $y$-axis indicates the scale for the lower panel. The endoglucanase activity from T. leycettanus is truncated. Error bars indicate standard deviations. See Table 1 for abbreviations of fungal names. The figure represents the result of triple determination of the enzyme activity for each culture in one growth experiment. The growth experiment was repeated twice with similar results.

The relatively broad $\mathrm{pH}$ optima measured for fungi like $C$. senegalense and T. indicae-seudaticae indicate that these fungi are able to degrade cellulose in environments with different $\mathrm{pH}$ values (Figure 2). The broad $\mathrm{pH}$ optimum may be due to one enzyme, which is active at several $\mathrm{pH}$ values, or to different enzymes with different $\mathrm{pH}$ optima. The only fungus among the species studied with highest activity at high $\mathrm{pH}$ value was the zygomycete T. indicae-seudaticae.

To assess thermostability of the endoglucanase activity the fungal extracts were incubated at $70^{\circ} \mathrm{C}$ for one hour before activity measurement. The activity after incubation at $50^{\circ} \mathrm{C}$ for one hour was used as reference. Thermostability varied from practically $100 \%$ activity after incubation at $70^{\circ} \mathrm{C}$ for one hour for the zygomycete $T$. indicae-seudaticae to almost complete loss of activity for the ascomycete Thermomyces lanuginosus (Eurotiales, Figure 3).

To access the total cellulolytic potential of the secretome from the 13 fungi with endoglucanase activity we measured the activity of the culture supernatants in a filter paper degradation assay. Degradation of filter paper requires the combined activity of both endo- and exocellulases and is often used as a measure of total cellulolytic potential (Dashtban et al. 2010; Zhang et al. 2009).

The T. leycettanus secretome showed more than 50 times higher cellulolytic activity as measured in the filter paper assay than the second most active secretome (Figure $4, P=0.003$, Student's T-test). Although only $23 \%$ of the activity remained after incubation at $70^{\circ} \mathrm{C}$ for one hour this is still much higher cellulolytic potential than the initial cellulolytic potential of any of the other fungi (Figure 5, $P=0.03$, Student's T-test)).

The loss of cellulolytic potential of $T$. leycettanus at $70^{\circ} \mathrm{C}$ does not correlate with the high thermostability of the endoglucanase activity of this fungus. This suggests that one or more of the cellobiohydrolases, monooxygenases or auxiliary enzymes that are involved in filter paper degradation are heat labile.

For T. leycettanus and the 12 other fungi where the endoglucanase activity was measurable this activity was either higher than the filter paper degrading activity or the

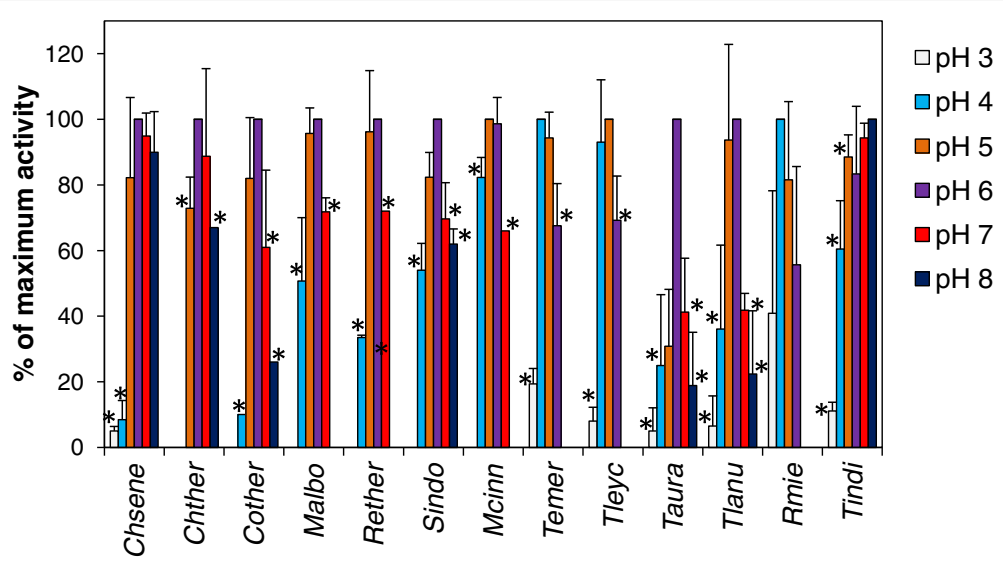

Figure 2 Optimal pH for the secreted endoglucanase activities. The culture supernatants from fungi grown on microcrystalline cellulose were brought to the $\mathrm{pH}$ indicated and the endoglucanase activity was measured. Activities are given as percent of the maximal measured endoglucanase activity. The experiment was repeated three times. The activities were determined as described in "Methods". Error bars indicate standard deviations. See Table 1 for abbreviations of fungal names. Stars next to bars indicates that the activity at this pH was significantly lower than the highest activity $(P<0.05$, Student's T-test). 


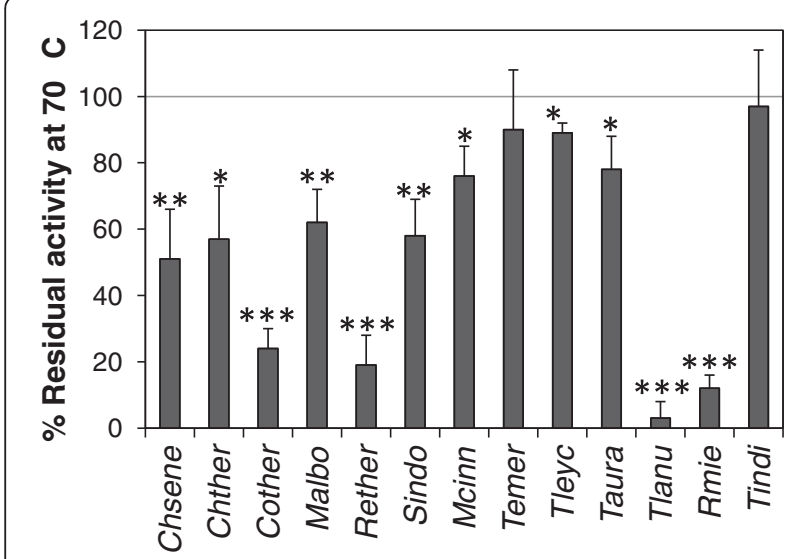

Figure 3 Heat stability of the secreted endoglucanase activities. Aliquots of the culture supernatants from fungi grown on microcrystalline cellulose were incubated for one hour at $70^{\circ} \mathrm{C}$ before measuring the endoglucanase activity (see "Methods"). Activities are given as percent remaining activity after one hour incubation at $70^{\circ} \mathrm{C}$ compared to control samples incubated at $50^{\circ} \mathrm{C}$. The experiment was repeated three times. Error bars indicate standard deviations. Stars next to bars indicate that the activity at this $\mathrm{pH}$ was significantly lower than the highest activity ( 1 star: $P<0.05,2$ stars: $P<0.01,3$ stars: $P<0.001$, Student's T-test). See Table 1 for abbreviations of fungal names.

filter paper degrading was too low to detect (Figures 2 and $4, P<0.001$, Student's T-test). This result suggests that the release of cellulose polymers from an insoluble substrate is rate limiting compared to the decomposition of the released cellulose into oligomers. However, the data

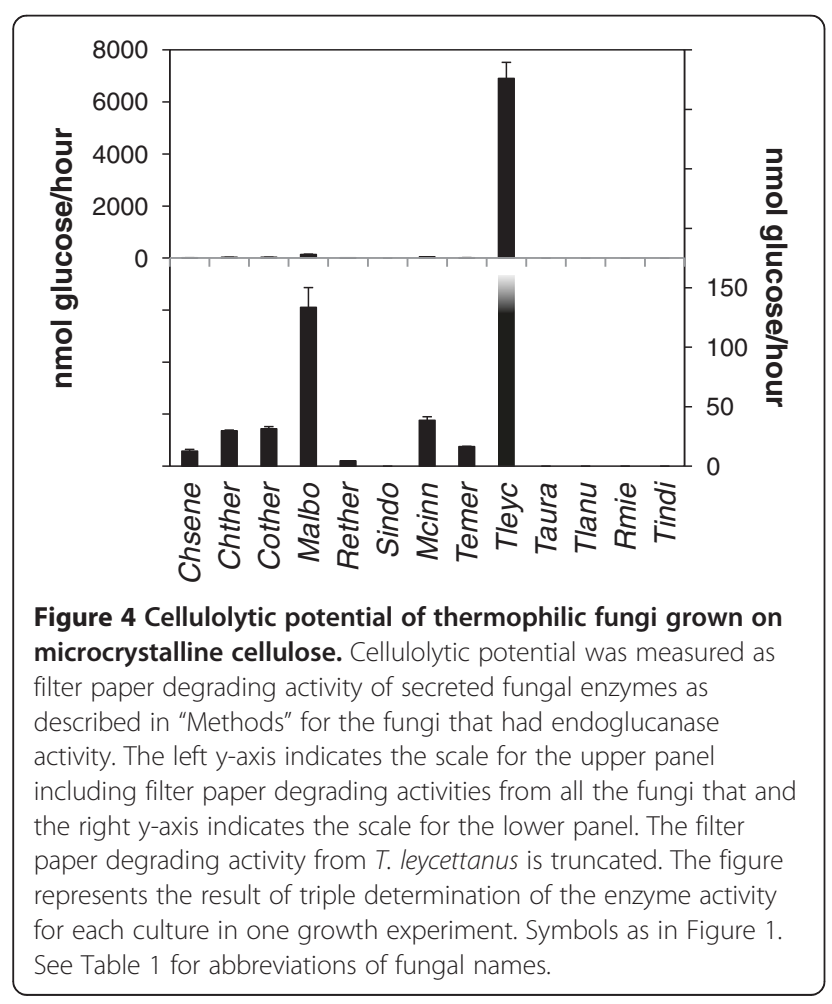

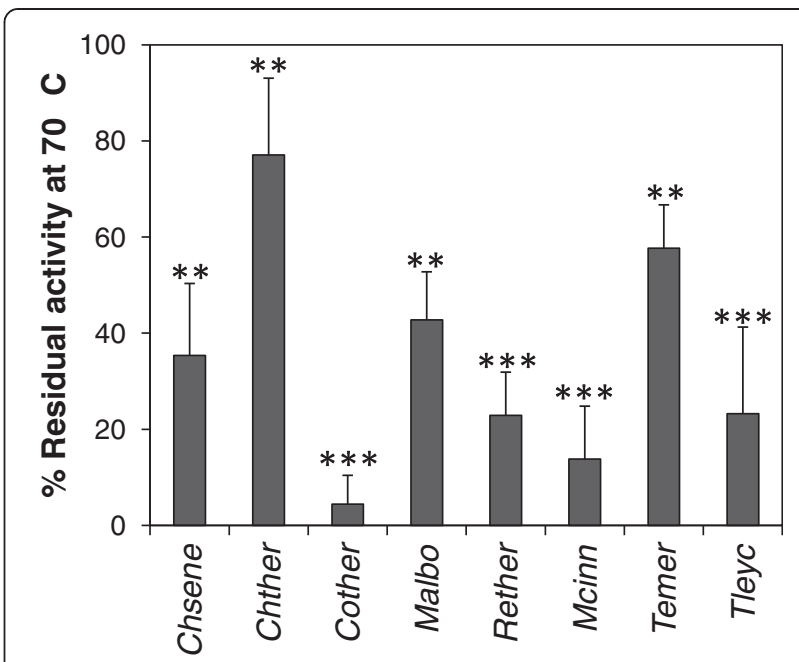

Figure 5 Heat stability of the secreted cellulolytic enzymes.

Aliquots of the culture supernatants from fungi grown on microcrystalline cellulose were incubated for one hour at $70^{\circ} \mathrm{C}$ before measuring the filter paper degrading activity (see "Methods"). Activities are given as percent remaining activity after one hour incubation at $70^{\circ} \mathrm{C}$ percent compared to control samples incubated at $50^{\circ} \mathrm{C}$. The experiment was repeated three times. Error bars indicate standard deviations. Stars next to bars indicate that the activity at this $\mathrm{pH}$ was significantly lower than the highest activity (1 star: $P<0.05,2$ stars: $P<0.01,3$ stars: $P<0.001$, Student's T-test). See Table 1 for abbreviations of fungal names.

should be interpreted with care as it is difficult to compare activities measured in different assays towards different substrates.

To determine if the fungi have genes encoding endoglucanases and cellobiohydrolases we designed degenerated primers for PCR amplification of the GH45 endoglucanases and the GH6 and GH7 cellobiohydrolases. With these primers it was possible to amplify and sequence partial genes for six GH6, eight GH7 and eight GH45 from the fungi. All sequences were submitted to the European Nucleotide Archive database except for the GH7 from Rhizomucor miehei that can be found in Additional file 1 . Expression of the genes was confirmed by RT-PCR of RNA isolated from fungi cultivated on microcrystalline cellulose medium (data not shown).

Together with the genes sequenced by others this provides positive confirmation that GH6, GH7 and GH45 are found in all three thermophilic orders of the Ascomycota and GH7 and GH45 are present in the Mucorales (Table 3). No GH6 were found in the two fungi of the order Mucorales but it cannot be excluded that $T$. indicae-seudaticae and $R$. miehei have genes encoding GH6 enzymes but that these genes were not amplified by the primers used in the present study.

Phylogenetic analysis did not reveal any correlation between the thermostability and activity of the enzyme activity and the protein sequences (Figure 6). 
Table 3 Genes encoding GH6, GH7 and GH45 enzymes sequenced in this study or found in GenBank

\begin{tabular}{|c|c|c|c|}
\hline Fungus & GH6 & GH7 & GH45 \\
\hline C. senegalense & HG313865 & HG313873a & $\mathrm{HG} 313881^{a}$ \\
\hline C. thermophilum & AAY88915.1 ${ }^{b}$ & AAW64926.1 b & EGS20050.1 ${ }^{\mathrm{b}}$ \\
\hline C. thermophilus & $H G 313866^{a}$ & HG313874 & $\mathrm{HG} 313883^{\mathrm{a}}$ \\
\hline M. albomyces & CAH05671. $1^{\mathrm{b}}$ & CAD56667. $1^{\mathrm{b}}$ & CAD56665.1 ${ }^{\mathrm{b}}$ \\
\hline R. thermophila & $H G 313871^{a}$ & $H G 313878^{a}$ & $H G 313886^{a}$ \\
\hline S. indonesiacum & $\mathrm{HG} 313872^{\mathrm{a}}$ & HG313879a & HG313887 \\
\hline S. thermophilum & BAB39154.1 ${ }^{b}$ & BAA09785.1 ${ }^{b}$ & BAA74956. $1^{b}$ \\
\hline M. cinnamomea & CAH05679.1 ${ }^{\mathrm{b}}$ & HG313889a & HG313885 \\
\hline T. byssochlamydoides & $H G 313868^{a}$ & $H G 313876^{a}$ & $N R^{c}$ \\
\hline T. emersonii & AAL33604.4 & AAL33603. $2^{\mathrm{b}}$ & CAJ75963.1 ${ }^{\mathrm{b}}$ \\
\hline T. leycettanus & HG313869a & $\mathrm{HG} 313877^{\mathrm{a}}$ & $N R^{c}$ \\
\hline T. thermophilus & $N^{c}$ & $N R^{c}$ & $N R^{c}$ \\
\hline T. aurantiacus & $N R^{c}$ & CAM98447. $1^{\mathrm{b}}$ & $H G 313884^{a}$ \\
\hline T. lanuginosus & $N R^{c}$ & ABR57319.1 ${ }^{\mathrm{b}}$ & $N R^{c}$ \\
\hline R. miehei & $N R^{c}$ & This study ${ }^{\mathrm{a}, \mathrm{d}}$ & HG313888 \\
\hline T. indicae-seudaticae & $N R^{c}$ & $N R^{c}$ & HG313880a \\
\hline
\end{tabular}

aThis study.

${ }^{\mathrm{b}}$ GenBank.

${ }^{\mathrm{C}} \mathrm{NR}$ : Not reported.

${ }^{\mathrm{d}}$ Too short sequence for submission to the public databases but can be found as Additional file 1.

\section{Discussion}

In the present study we have assessed the cellulolytic potential of isolates of 16 different thermophilic fungi belonging to four orders by checking their growth on microcrystalline cellulose and characterizing their secreted cellulose-degrading enzymatic activities.

All of the fungal strains could grow on microcrystalline cellulose and were therefore able to degrade cellulose. Two of the fungi ( $T$. leycettanus and $T$. aurantiacus) needed a supplement of yeast extract for growth. Two observations point to that the growth of these two fungi on cellulose was not limited by access to carbon but rather by some other factor that could be provided by the yeast extract. Firstly, yeast extract contains $0.4 \mathrm{~g}$ carbon per g (Holwerda et al. 2012). Therefore, the total contribution of non-cellulose carbon from the yeast extract is $0.2 \%$, which will only allow limited growth of the fungi. Secondly, T. aurantiacus only grew poorly and $T$. leycettanus not at all on cellulose medium when the medium was supplemented with easily fermentable carbon in the form of $1 \%$ glucose (data not shown). Therefore it was not the amount of available carbon per se that was growth limiting. In support of this notion, T. leycettanus was very capable of degrading cellulose as the enzyme assays showed that it secreted by far the highest amount of cellulases of all the fungi tested.

Interestingly, the $M$. albomyces strain, which was isolated from chicken nest straw in Nevada, grew readily on the cellulose medium in contrast to what was previously reported for a strain of $M$. albomyces isolated from forest soil and compost in India (Maheshwari and Kamalam 1985). This suggests that different isolates of $M$. albomyces have different cellulolytic potential. Moreover, the $M$. albomyces strain used in the present study was the fungus with the second highest cellulolytic potential thereby supporting the notion that this strain is able to degrade cellulose in contrast to the previously characterized strain (Maheshwari and Kamalam 1985).

This difference suggests that it is difficult to conclude about growth preferences of a fungal species based on the study of a single strain. It is tempting to speculate that the original biotope of the strain used in the present study had higher cellulose content than the biotope of the strain used by Maheshwari and Kamalam (Maheshwari and Kamalam 1985).

Likewise, T. lanuginosus is generally considered to be unable to utilize cellulose as sole carbon source (Maheshwari et al. 2000) in contrast to the observation in the present study. However, different strains of $T$. lanuginosus have different ability to grow on cellulose (Markowska-Szczupak et al. 2012) in agreement with that there can be large differences in the cellulolytic potential of different isolates of the same species.

This notion is supported by the absence of detectable endoglucanase activity from the strain of $S$. thermophilum used in the present study whereas it has been reported that other strains of $S$. thermophilum produce endoglucanase and other cellulases when grown on recalcitrant polysaccharides (Hayashida and Mo 1986; Ögel et al. 2001; Poças-Fonseca et al. 2000).

It is difficult to account for that some of the fungi e.g. $S$. thermophilum could grow on cellulose without producing any detectable endoglucanase activity. It cannot be completely ruled out that the cellulose-degrading activity is membrane associated but it is highly unlikely as no endoglucanase activity was detected in the supernatant from homogenized mycelium (data not shown). Furthermore, it is quite unusual for fungal cellulases to be membrane-anchored although it has been reported. One example is a membrane-anchored endoglucanase that was cloned from Phanerochaete chrysosporium (Vanden Wymelenberg et al. 2002). Another possibility is that $S$. thermophilum uses a different mechanism such as oxidative processes to degrade the cellulose (Arantes et al. 2011; Rineau et al. 2012). However, this fungus can express cellulose-degrading activity (Ögel et al. 2001) and has genes encoding endoglucanases (Takashima et al. 1999).

One purpose of the present study was to elucidate whether it is possible to predict high thermostability from fungal taxonomy. However, there was no obvious correlation between the fungal orders and the thermostability but at genus level the enzymes from the two 


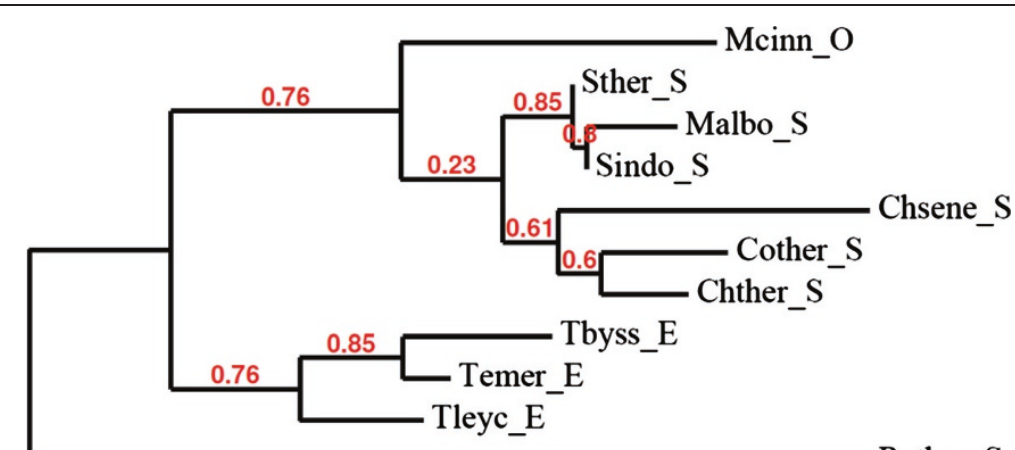

Rether_S

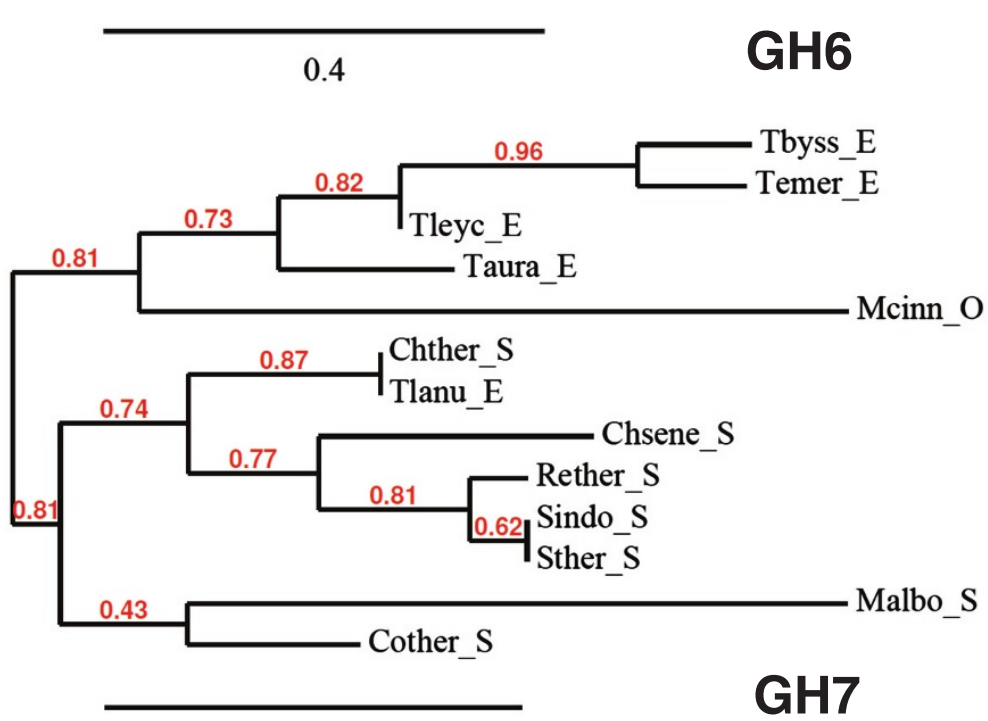

0.2

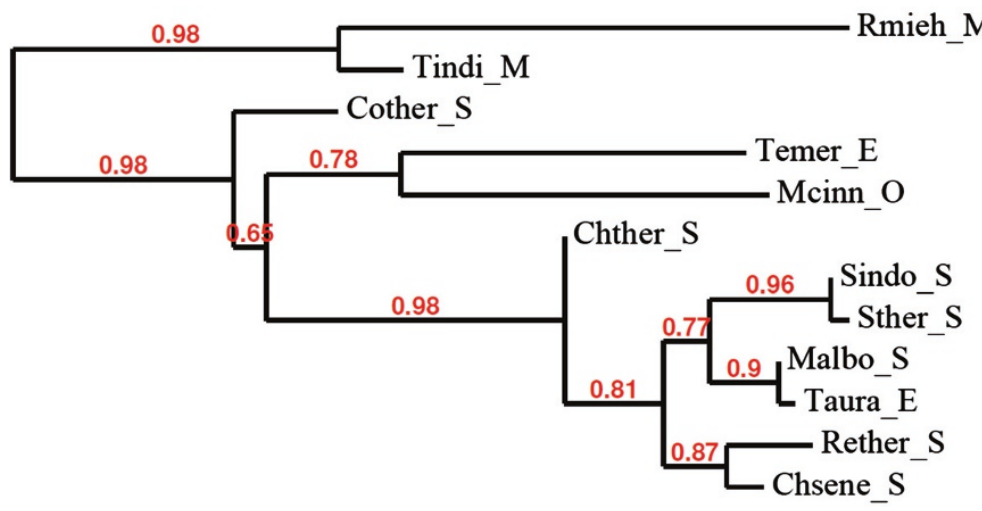

0.4

\section{GH45}

Figure 6 Phylogeny of sequenced genes encoding GH6, GH7 and GH45 family proteins from the thermophilic fungi. All the genes sequenced in the present study except GH7 from R. miehei that was too short to produce any significant alignment and the genes found in NCBI (see Table 3) were aligned with MUSCLE before curating the alignments with Gblocks and building of phylogenetic trees with PhyML (Dereeper et al. 2008). The three were depicted with TreeDyn. O: Onygenales; S: Sordariales; E: Eurotiales; M: Mucorales. See Table 1 for abbreviations of fungal names.

species of Talaromyces with measurable endoglucanase activity showed high thermostability. As the cellulolytic potential of some of the isolates used in the present study was different from the cellulolytic potential reported for other isolates of the same species (Hayashida and Mo 1986; Maheshwari et al. 2000; Maheshwari and Kamalam 1985; Markowska-Szczupak et al. 2012; Ögel et al. 2001; Poças-Fonseca et al. 2000) it is likely that 
the thermostability of enzymes may vary between isolates of the same species. However, the high thermostability observed for the enzyme activity from T. emersonii and T. aurantiacus (both Eurotiales) is in agreement with previous reports on these fungi (Gomes et al. 2000; Hong et al. 2003; Khandke et al. 1989; McClendon et al. 2012; Murray et al. 2004; Parry et al. 2002; Romanelli et al. 1975; Voutilainen et al. 2010).

Just like the taxonomy, the predicted protein sequences of the sequenced genes did not exhibit any correlation to the thermostability of the cellulose-degrading activity. Instead the protein sequences grouped largely according to the taxonomic order with a few exceptions. E.g., the GH45 sequences from Corynascus thermophilus did not fall in the same branch of the phylogenetic tree as the other GH45 from Sordariales. Moreover, the GH45 protein from $T$. aurantiacus shows higher relationship to the protein from M. albomyces from Sordariales than to the protein for the other fungus of the Eurotiales order, T. emersonii. Similar results were found for the DNA sequences of the enzyme-encoding genes (Additional file 2).

One curious result was that no GH6 encoding genes were found in the two fungi of the order Mucorales. Although it is possible that these fungi have some GH6 genes that were simply not found in the present study, it is interesting that another Zygomycota of the Mucorales order, Rhizopus oryzae, is able to degrade cellulose despite the absence of any GH6 gene in its genome (Battaglia et al. 2011).

The high pH optimum of the cellulolytic activity from $T$. indicae-seudaticae distinguished this fungus from the other fungi. Also a purified glucoamylase from T. indicae-seudaticae has a relatively high $\mathrm{pH}$ optimum (Kumar and Satyanarayana 2003) suggesting that this fungus may be adapted to growth in an environment with high $\mathrm{pH}$.

For six of the eight fungi where high activity was measured in both assays the endoglucanase activity was more heat stable than the filter paper degrading activity (Figure 3 and $5, P=0.012$, Student's T-test). This is in agreement with that more enzymes including endoglucanases are necessary for filter paper degradation than for decomposition of carboxy-methyl cellulose (reviewed by (Dashtban et al. 2010)). In view of this it seems surprising that $C$. thermophilum exhibited more stable filter paper degrading activity than endoglucanase activity (Figures 3 and 5). This can be explained by the finding that the endoglucanase activity of $C$. thermophilum measured as $\mu$ moles of glucose released per hour was almost 70 times higher than the filter paper degrading activity. Therefore the endoglucanase activity was not rate limiting for the total cellulolytic potential of the fungus.

In conclusion, the results of the present study show that thermophilic fungi of all four orders from where thermophilic species have been described, are able to degrade cellulose. The main differences in cellulolytic potential and thermostability of the secretome do not seem to correlate to the fungal order.

\section{Additional files}

Additional file 1: Sequence of the GH7 gene fragment from $\boldsymbol{R}$.

miehei. DNA sequence of the truncated $\mathrm{GH} 7$ gene that was amplified and sequenced from $R$. miehei. The lower sequence is the amino acid sequence of the fragment translated in the frame that resembles a $\mathrm{GH} 7$ family protein.

Additional file 2: Phylogenetic relationship of the DNA sequences encoding enzymes belonging to the $\mathrm{GH} 6, \mathrm{GH} 7$ and $\mathrm{GH} 45$ families from the thermophilic fungi.

\section{Competing interests}

Both authors are designated as inventors of a patent on the cloned genes originally filed by Aalborg University and later transferred to Novozymes A/S. Neither of the authors have any personal financial interests in the patent but part of the authors' research is funded through a grant from Novozymes A/S.

\section{Acknowledgments}

We thank Mette Lange and Morten Nedergaard Grell for constructive and insightful suggestions.

This work was supported by The Danish Strategic Research Council project 2101-08-0041 (BioRef) and by Novozymes A/S.

Received: 9 August 2013 Accepted: 11 August 2013

Published: 19 August 2013

\section{References}

Altschul SF, Madden TL, Schäffer AA, Zhang J, Zhang Z, Miller W, Lipman DJ (1997) Gapped BLAST and PSI-BLAST: a new generation of protein database search programs. Nucleic Acids Res 25:3389-3402

Andersen MD, Busk PK, Svendsen I, Møller BL (2000) Cytochromes P-450 from cassava (Manihot esculenta Crantz) catalyzing the first steps in the biosynthesis of the cyanogenic glucosides linamarin and lotaustralin. Cloning, functional expression in Pichia pastoris, and substrate specificity of the isolated recombinant enzymes. J Biol Chem 275:1966-1975

Arantes V, Milagres AMF, Filley TR, Goodell B (2011) Lignocellulosic polysaccharides and lignin degradation by wood decay fungi: the relevance of nonenzymatic Fenton-based reactions. J Ind Microbiol Biotechnol 38:541-555

Balcells I, Cirera S, Busk PK (2011) Specific and sensitive quantitative RT-PCR of miRNAs with DNA primers. BMC Biotechnol 11:70

Banerjee G, Car S, Scott-Craig JS, Borrusch MS, Aslam N, Walton JD (2010) Synthetic enzyme mixtures for biomass deconstruction: production and optimization of a core set. Biotechnol Bioeng 106:707-20

Battaglia E, Benoit I, van den Brink J, Wiebenga A, Coutinho PM, Henrissat B, de Vries RP (2011) Carbohydrate-active enzymes from the zygomycete fungus Rhizopus oryzae: a highly specialized approach to carbohydrate degradation depicted at genome level. BMC Genomics 12:38

Berka RM, Grigoriev IV, Otillar R, Salamov A, Grimwood J, Reid I, Ishmael N, John T, Darmond C, Moisan MC, Henrissat B, Coutinho PM, Lombard V, Natvig DO, Lindquist E, Schmutz J, Lucas S, Harris P, Powlowski J, Bellemare A, Taylor D, Butler G, de Vries RP, Allijn IE, van den Brink J, Ushinsky S, Storms R, Powell AJ, Paulsen IT, Elbourne LD, Baker SE, Magnuson J, Laboissiere S, Clutterbuck AJ, Martinez D, Wogulis M, de Leon AL, Rey MW, Tsang A (2011) Comparative genomic analysis of the thermophilic biomass-degrading fungi Myceliophthora thermophila and Thielavia terrestris. Nat Biotech 29:922-927

Chen C, Ridzon DA, Broomer AJ, Zhou Z, Lee DH, Nguyen JT, Barbisin M, Xu NL, Mahuvakar VR, Andersen MR, Lao KQ, Livak KJ, Guegler KJ (2005) Real-time quantification of microRNAs by stem-loop RT-PCR. Nucleic Acids Res 33:e179 Dashtban M, Schraft H, Qin W (2009) Fungal bioconversion of lignocellulosic residues; opportunities \& perspectives. Int J Biol Sci 5:578-595 
Dashtban M, Maki M, Leung KT, Mao C, Qin W (2010) Cellulase activities in biomass conversion: measurement methods and comparison. Crit Rev Biotechnol 30:302-309

Dereeper A, Guignon V, Blanc G, Audic S, Buffet S, Chevenet F, Dufayard JF, Guindon S, Lefort V, Lescot M, Claverie JM, Gascuel O (2008) Phylogeny.fr: robust phylogenetic analysis for the non-specialist. Nucleic Acids Res 36: W465-469

Gomes I, Gomes J, Gomes DJ, Steiner W (2000) Simultaneous production of high activities of thermostable endoglucanase and $\beta$-glucosidase by the wild thermophilic fungus Thermoascus aurantiacus. Appl Microbiol Biotechnol 53:461-468

Harris PV, Welner D, McFarland KC, Re E, Navarro Poulsen JC, Brown K, Salbo R Ding H, Vlasenko E, Merino S, Xu F, Cherry J, Larsen S, Lo Leggio L (2010) Stimulation of lignocellulosic biomass hydrolysis by proteins of glycoside hydrolase family 61: structure and function of a large, enigmatic family. Biochemistry 49:3305-3316

Hayashida S, Mo K (1986) Production and characteristics of avicel-disintegrating endoglucanase from a protease-negative Humicola grisea var. thermoidea mutant. Appl Environ Microbiol 51:1041-1046

Henrissat B, Davies G (1997) Structural and sequence-based classification of glycoside hydrolases. Curr Opin Struct Biol 7:637-644

Herr D (1979) Secretion of cellulase and $\beta$-glucosidase by Trichoderma viride ITCC-1433 in submerged culture on different substrates. Biotechnol Bioeng 21:1361-1371

Hong J, Tamaki H, Yamamoto K, Kumagai H (2003) Cloning of a gene encoding thermostable cellobiohydrolase from Thermoascus aurantiacus and its expression in yeast. Appl Microbiol Biotechnol 63:42-50

Hong J, Tamaki H, Kumagai H (2007) Cloning and functional expression of thermostable $\beta$-glucosidase gene from Thermoascus aurantiacus. App Microbiol Biotechnol 73:1331-1339

Johri BN, Satyanarayana T, Olsen J (1999) Thermophilic moulds in biotechnology, 1st edn. Kluwer Academic Publishers, Dordrecht, The Netherlands

Karmakar M, Ray RR (2011) Current trends in research and application of microbial cellulases. Res J Microbiol 6:41-53

Khandke KM, Vithayathil PJ, Murthy SK (1989) Purification of xylanase, $\beta$-glucosidase, endocellulase, and exocellulase from a thermophilic fungus, Thermoascus aurantiacus. Arch Biochem Biophys 274:491-500

Kuhad RC, Gupta R, Singh A (2011) Microbial cellulases and their industrial applications. Enzyme Res 2011:1-10

Kumar S, Satyanarayana T (2003) Purification and kinetics of a raw starchhydrolyzing, thermostable, and neutral glucoamylase of the thermophilic mold Thermomucor indicae-seudaticae. Biotechnol Prog 19:936-944

Langston JA, Shaghasi T, Abbate E, Xu F, Vlasenko E, Sweeney MD (2011) Oxidoreductive cellulose depolymerization by the enzymes cellobiose dehydrogenase and glycoside hydrolase 61. Appl Environ Microbiol 77:7007-7015

Larkin MA, Blackshields G, Brown NP, Chenna R, McGettigan PA, McWilliam H, Valentin F, Wallace IM, Wilm A, Lopez R, Thompson JD, Gibson TJ, Higgins DG (2007) Clustal W and Clustal X version 2.0. Bioinformatics 23:2947-2948

Maheshwari R, Kamalam PT (1985) Isolation and culture of a thermophilic fungus, Melanocarpus albomyces, and factors influencing the production and activity of xylanase. J Gen Microbiol 131:3017-3027

Maheshwari R, Bharadwaj G, Bhat MK (2000) Thermophilic fungi: their physiology and enzymes. Microbiol Mol Biol Rev 64:461-488

Marchler-Bauer A, Lu S, Anderson JB, Chitsaz F, Derbyshire MK, DeWeese-Scott C, Fong JH, Geer LY, Geer RC, Gonzales NR, Gwadz M, Hurwitz DI, Jackson JD, Ke Z, Lanczycki CJ, Lu F, Marchler GH, Mullokandov M, Omelchenko MV, Robertson CL, Song JS, Thanki N, Yamashita RA, Zhang D, Zhang N, Zheng C, Bryant SH (2011) CDD: a conserved domain database for the functional annotation of proteins. Nucleic Acids Res 39:D225-229

Markowska-Szczupak A, Ulfig K, Janda K (2012) The growth of Thermomyces lanuginosus (TSIKL.) isolates from garden composts and coffee beans on cellulose substrates and xylan at various water activity. Arch Environ Protection 38:73-80

McClendon SD, Baath T, Petzold CJ, Adams PD, Simmons BA, Singer SW (2012) Thermoascus aurantiacus is a promising source of enzymes for biomass deconstruction under thermophilic conditions. Biotechnology for Biofuels 5:54

Mcllvaine TC (1921) A buffer solution for colorimetric comparison. J Biol Chem 49:183-186

Morgenstern I, Powlowski J, Ishmael N, Darmond C, Marqueteau S, Moisan MC, Quenneville G, Tsang A (2012) A molecular phylogeny of thermophilic fungi. Fungal Biol 116:489-502
Murray P, Aro N, Collins C, Penttilä M, Saloheimo M, Tuohy M (2004) Expression in Trichoderma reesei and characterisation of a thermostable family 3 $\beta$-glucosidase from the moderately thermophilic fungus Talaromyces emersonii. Protein Expr Purif 38:248-257

Ögel ZB, Yarangümeli K, Dü H, Ifrij I (2001) Submerged cultivation of Scytalidium thermophilum on complex lignocellulosic biomass for endoglucanase production. Enzyme Microb Technol 28:689-695

Parry NJ, Beever DE, Owen E, Vandenberghe I, Van Beeumen J, Bhat MK (2001) Biochemical characterization and mechanism of action of a thermostable $\beta$ glucosidase purified from Thermoascus aurantiacus. Biochem J 353:117-127

Parry NJ, Beever DE, Owen E, Nerinckx W, Claeyssens M, Van Beeumen J, Bhat MK (2002) Biochemical characterization and mode of action of a thermostable endoglucanase purified from Thermoascus aurantiacus. Arch Biochem Biophys 404:243-253

Poças-Fonseca MJ, Silva-Pereira I, Rocha BB, De Azevedo M (2000) Substrate-dependent differential expression of Humicola grisea var. thermoidea cellobiohydrolase genes. Can J Microbiol 46:749-752

Quinlan RJ, Sweeney MD, Lo Leggio L, Otten H, Poulsen JC, Johansen KS, Krogh KB, Jørgensen Cl, Tovborg M, Anthonsen A, Tryfona T, Walter CP, Dupree P, Xu F, Davies GJ, Walton PH (2011) Insights into the oxidative degradation of cellulose by a copper metalloenzyme that exploits biomass components. Proc Natl Acad Sci USA 108:15079-15084

Rineau F, Roth D, Shah F, Smits M, Johansson T, Canbäck B, Olsen PB, Persson P, Grell MN, Lindquist E, Grigoriev IV, Lange L, Tunlid A (2012) The ectomycorrhizal fungus Paxillus involutus converts organic matter in plant litter using a trimmed brown-rot mechanism involving Fenton chemistry. Environ Microbiol 14:1477-1487

Romanelli RA, Houston CW, Barnett SM (1975) Studies on thermophilic cellulolytic fungi. Appl Microbiol 30:276-281

Roy SK, Dey SK, Raha SK, Chakrabarty SL (1990) Purification and properties of an extracellular endoglucanase from Myceliophthora thermophila D-14 (ATCC 48104). J Gen Microbiol 136:1967-1971

Takashima S, likura H, Nakamura A, Hidaka M, Masaki H, Uozumi T (1999) Comparison of gene structures and enzymatic properties between two endoglucanases from Humicola grisea. J Biotechnol 67:85-97

Vanden Wymelenberg A, Denman S, Dietrich D, Bassett J, Yu X, Atalla R, Predki P, Rudsander U, Teeri TT, Cullen D (2002) Transcript Analysis of Genes Encoding a Family 61 Endoglucanase and a Putative Membrane-Anchored Family 9 Glycosyl Hydrolase from Phanerochaete chrysosporium. Appl Environ Microbiol 68:5765-5768

Venturi LL, de Polizeli M, Terenzi L, Furriel HF, Rdos P, Jorge JA (2002) Extracellular $\beta$-D-glucosidase from Chaetomium thermophilum var. coprophilum: production, purification and some biochemical properties. J Basic Microbiol 42:55-66

Viikari L, Alapuranen M, Puranen T, Vehmaanperä J, Siika-Aho M (2007) Thermostable enzymes in lignocellulose hydrolysis. Adv Biochem Eng Biotechnol 108:121-145

Voutilainen SP, Puranen T, Siika-Aho M, Lappalainen A, Alapuranen M, Kallio J, Hooman S, Viikari L, Vehmaanperä J, Koivula A (2008) Cloning, expression, and characterization of novel thermostable family 7 cellobiohydrolases. Biotechnol Bioeng 101:515-528

Voutilainen SP, Murray PG, Tuohy MG, Koivula A (2010) Expression of Talaromyces emersonii cellobiohydrolase Cel7A in Saccharomyces cerevisiae and rational mutagenesis to improve its thermostability and activity. Protein Eng Des Sel 23:69-79

Westereng B, Ishida T, Vaaje-Kolstad G, Wu M, Eijsink VG, Igarashi K, Samejima M, Ståhlberg J, Horn SJ, Sandgren M (2011) The putative endoglucanase PcGH61D from Phanerochaete chrysosporium is a metal-dependent oxidative enzyme that cleaves cellulose. PLOS ONE 6:e27807

Wojtczak G, Breuil C, Yamada J, Saddler JN (1987) A comparison of the thermostability of cellulases from various thermophilic fungi. Appl Microbiol Biotechnol 27:82-87

Zhang YHP, Hong J, Ye X (2009) Cellulase assays. Methods Mol Biol 581:213-231

doi:10.1186/2191-0855-3-47

Cite this article as: Busk and Lange: Cellulolytic potential of thermophilic species from four fungal orders. AMB Express 2013 3:47. 